\title{
Resenhas
}

CARIDE, José Antonio. Las fronteras de la pedagogia social. Perspectivas científica e histórica. Barcelona: Gedisa, 2005. 285 p.

\section{A pedagogia social e as racionalidades do campo socioeducativo}

A obra As fronteiras da pedagogia social. Perspectivas científica e histórica, de José Antonio Caride, professor da Universidade de Santiago de Compostela (Espanha) e presidente da Sociedade Ibero-Americana de Pedagogia Social, é um tratado que busca evidenciar a construção do estatuto científico da pedagogia social a partir de estudos realizados por pesquisadores da área, como Violeta Nuñez, Jaume Trilla Bernet, José Ortega Esteban, Antonio Petrus, entre outros.

O livro é a síntese do processo que resultou na cátedra de professor titular da Universidade de Santiago de
Compostela, no ano de 2005, e está dividido em duas partes: "A pedagogia social como ciência pedagógica e social" e "A pedagogia social como construção histórica”. É a partir do movimento entre os critérios de cientificidade e a revisão histórica de inúmeras obras e autores que surge a metáfora das fronteiras, utilizada pelo autor.

Embora, no Brasil, existam poucos estudos nessa área do conhecimento, na Europa, em especial na Espanha, muitas são as produções sobre a pedagogia social como ciência da educação. A emergência dessa prática pedagógica é datada no século XIX, na Alemanha, mas é ao longo do século XX que a pedagogia social se consolida e se transforma em formação acadêmica.

Como contraponto, no Brasil de hoje multiplicam-se práticas socioeducativas que prescindem de base teóricometodológica em que a educação aparece como qualificativo do social, ou melhor, da ação assistencial. Aqui, ainda prevalece a idéia de que a educação é prática eminentemente escolar e que as ações do campo social podem ser realizadas por pessoas leigas e com baixa escolarização.

Nesse sentido, a obra de Caride é reveladora ao reivindicar maior protagonismo à educação na vida cotidiana e na garantia da cidadania ativa e, para tanto, analisa o lugar da pedagogia social como ciência das humanidades e do social. Parte do contexto da ciência moderna e sua importância para o desenvolvimento da era industrial, ao mesmo tempo em que apresenta os limites éticos e o potencial de risco que ameaça o futuro da humanidade diante do abuso do saber científico. Crítico da supremacia do método, em especial dos modos de concebê-lo e aplicá-lo, reconhece que resulta impossível imaginar o avanço da ciência prescindindo da objetividade e do rigor inerente ao método. Reforça, outrossim, para destacar a inexistência da unicidade do método científico, que: a) cada disciplina científica tem exigências particulares; e b) devemos optar por um método 
em função do tipo de conhecimento que pretendemos produzir.

Do reconhecimento da curiosidade universal, o autor reforça a indissociabilidade entre ciência e filosofia. Da primeira resgata o rigor, a clareza conceitual e a constatação empírica das representações e, da segunda, por uma inspiração ainda não realizada, reforça a relação entre ambas. A partir desse contexto e considerando os quesitos para que um conhecimento receba o atributo de científico, Caride afirma que a pedagogia social é uma ciência em construção, cuja provisoriedade destaca a dúvida sistemática, a perplexidade e a curiosidade. Com denso percurso histórico, agrega conhecimento aos saberes pedagógicos e sociais e às práticas exercidas por pessoas e por instituições.

O caminho realizado pelo autor para definir a pedagogia social como ciência envolve linhas de investigação em cursos de graduação e pósgraduação. As pesquisas sustentam aproximações com saberes acadêmicos e compartilham consensos produzidos pelas comunidades científicas européias. Para tanto, Caride expressa a necessidade de demarcar um campo de reflexão, de estudo e de investigação que sustente uma disciplina científica relativamente autônoma que investigue, teorize, conceitualize, organize e sistematize conhecimentos relativos à prática profissional de educadores sociais; que reconheça a complexa realidade educativo-social e tenha possibilidade de transformá-la; que considere a origem ético-moral das ações e intervenções propostas e dos objetivos pedagógicos e sociais e que, em última instância, provoque mudanças na forma de ser e estar no mundo de sujeitos individuais e sociais.

A intencionalidade, por sua vez, constitui-se em um elemento fundamental para a construção epistemológica da pedagogia social, devendo justificar as razões pelas quais fundamenta a decisão de intervir. Afirmam Gleiber e Hege, citados por Caride (p. 14), que "[...] os processos de aprendizagem da reflexão crítica é orientação para uma ação inovadora" ao destacar a oportunidade do pedagogo social em atuar intencionalmente sobre situações problemáticas ou de conflito.

Assim, o livro aborda a pedagogia social como ciência, disciplina e profissão!

A obra demonstra que a pedagogia social/educação social e o trabalho social/serviço social compartilham práticas e objetivos que, por vezes, acabam por apresentar a pedagogia social como atividade pedagógica do trabalho social. Entretanto, apesar das convergências, o destaque dá-se por conta de que a pedagogia social e o serviço social são identificados como profissões distintas.

O trabalho social/serviço social sustenta-se sobre um ação-intervenção realizada em favor da defesa dos direitos da cidadania e do acesso aos serviços de bem-estar. A pedagogia social supera a lógica do bem-estar social para uma perspectiva complexa que se aproxima dos conceitos de qualidade de vida, desde intervenções e finalidades pedagógicas. Ambas, intervenções e finalidades, afirma o autor, promovem o desenvolvimento humano e a qualidade do viver. Tal afirmação considera duas orientações principais, tratadas na obra: a necessidade de enfrentamento às situações de risco que inibem ou dificultam a integração social, especialmente dos que estão mais expostos aos processos de exclusão social, precariedade e dependência, e a confirmação do compromisso de resgate de uma sociedade qualitativa e quantitativamente mais igualitária, justa e unida.

Com o firme propósito de reafirmar a pedagogia social como ciência, Caride ressalta o saber normativo per- tinente à ela, confirmando o sentido intencional, teleológico e axiológico dos processos educativos que concebem o dever pedagógico social como resposta reflexiva, consciente e estratégica. A natureza contextual das atuações teórico-práticas são apresentadas em dupla perspectiva: associa a emergência do desenvolvimento científico, acadêmico e profissional da pedagogia social às problemáticas educativas e sociais emergentes e, antevendo o futuro, prevê como desafio à profissão do pedagogo social a atuação sobre as novas formas de encaminhar o jogo social referente aos patrimônios e às heranças culturais.

Por sua vez, como ciência praxiológica que faz convergir conhecimento, reflexão e ação, destaca os vários caminhos para construir e aplicar os conhecimentos da pedagogia social. Valoriza o perfil crítico-reflexivo e dialético e destaca seis grandes áreas de atuação: a educação permanente, a formação laboral e ocupacional, a educação no/para o tempo livre, a animação sociocultural e o desenvolvimento comunitário, a educação especializada e a educação cívico-social.

Quanto à historiografia, o esforço concentra-se no tempo histórico e na relação deste com o contexto, isto é, busca elucidar os discursos que se fundam em determinados contextos sociais. Descreve a história das práticas assistenciais desde a sua origem ligada aos poderes políticos e às instituições religiosas para a cobertura das necessidades sociais, presentes na Idade Média. Na contemporaneidade, tais demandas se apresentam na forma de práticas de educação não-escolar que, com intervenções diversas, descortinam uma realidade que demanda formação profissional específica.

Para finalizar, Buj Gimeno, citado pelo autor, a partir dos estudos de educadores alemães, reforça a tese de que a pedagogia social é pedagogia 
e, portanto, define-se por sua dimensão social. Assim, na perspectiva dos pesquisadores da Alemanha, pensar a pedagogia como social traduz-se em uma redundância. A brasileira Marlene Ribeiro, 1 em artigo recente, também intensifica a tese de que toda a educação é social, e reforça a idéia da repetição presente em Gimeno e outros.

No Brasil, não está em pauta a formação acadêmica do pedagogo social, no entanto, estamos diante de um campo complexo e contraditório, o da educação no campo social. Da história da educação popular, em especial, a partir dos estudos de Paulo Freire, é possível verificar que ela tem sido metamorfoseada pela emergência das políticas públicas do terceiro setor, as quais evidenciam outros contornos à educação popular e comunitária. Os projetos socioeducativos voltados a populações vulnerabilizadas socialmente são um exemplo.

Não obstante, os estudos de Caride e dos demais autores citados por ele contribuem com uma área do conhecimento que, no Brasil, dá seus primeiros passos em direção à formação acadêmica ou em serviço de educadores sociais. Tal contribuição pode provocar um tensionamento na trajetória das práticas assistencialistas e compensatórias voltadas às populações mais vulnerabilizadas à medida que faz chegar à educação não-escolar questionamentos em torno da necessidade da sua profissionalização.

Um encontro qualificado da educação com o social demanda por uma aproximação com a pedagogia social, se não como profissão, nos moldes da Europa e alguns países da América Latina, ao menos como área transdis-

1 RIBEIRO, Marlene. Uma educação social faz sentido? Alguns apontamentos. S.d. Disponível em: <http://www.ufrgs.br/tramse/argos/edu/2004/06/uma-educa-brasil-16-de-abrilde-2004.html>. Acesso em: 4 de abril de 2006. ciplinar de conhecimento. Nessa perspectiva, pretendemos explorar outros cenários que vislumbrem a possibilidade de a educação constituir-se como direito e potência para os sujeitos, em um encontro com os outros e com o mundo. Sem perder de vista sua temporalidade, a sua necessária vinculação institucional sob a responsabilidade do Estado, a pedagogia social, desde a sua transversalidade, deverá agregar à educação valores que favorecem, entre outros, a emergência de uma cultura da solidariedade e uma ética do cuidado.

Dinora Tereza Zucchetti

Professora pesquisadora da Federação de Estabelecimento de Ensino Superior em Novo Hamburgo (FEEVALE), e membro do Grupo de Estudos Gestão do Cuidado em Educação (UFRGS) e do Grupo de Pesquisa Educação, Cultura e Trabalho (FEEVALE). E-mail:dinora@feevale.br

TRASSI, Maria de Lourdes. Adolescência-violência: desperdícios de vidas. São Paulo: Cortez, 2006. 264 pág.

No rol das temáticas controversas e polêmicas percebidas no âmbito social, a associação entre adolescentes e violência pode ser considerada uma construção bastante significativa, sobretudo, no momento presente. Nesse cenário é que são gestadas as relações abordadas pela autora, Maria de Lourdes Trassi, psicóloga e psicanalista, que conta com uma ampla trajetória profissional, na qual tem destaque práticas relacionadas aos adolescentes autores de ato infracional, tendo atuado na primeira unidade do sistema Fundação Estadual do Bem-Estar do Menor (FEBEM) na década de 1970, posteriormente, na década de 1980, sendo diretora da única unidade da FEBEM para jovens adultos.
O recorte histórico temporal da pesquisa relaciona-se ao período compreendido entre os anos de 1960 a 2005 tendo como lócus espacial a cidade de São Paulo. As problematizações apóiam-se em autores como Hobsbawm, Foucault, Heller, Adorno e Freud.

A pesquisa pauta-se na consideração da temática como uma realidade composta por numerosos determinantes, os quais se referem: ao modo de organização social, política e econômica; às novas tecnologias; às mudanças nas relações de gênero e na percepção da juventude, fundamentalmente em seus novos papéis sociais na família e na sociedade e sua incorporação ao mercado do consumo "de bens materiais e culturais".

Uma hipótese de pesquisa bastante importante para conceber a problemática levantada pela autora é a representação social existente e muito difundida acerca da responsabilidade dos adolescentes pelos elevados índices de criminalidade observados no âmbito nacional, visto que essa forma de representação é o que possibilita, por vezes, a justificação do uso pelo Estado de meios autoritários e repressivos e, em determinado casos, fornece legitimidade a mecanismos cruéis como a tortura e o extermínio.

Com relação ao processo metodológico desenvolvido, cabe destacar que contempla fontes documentais, constituídas de dados estatísticos, relatórios, estudos de casos, pesquisas científicas, entre outros. Além disso, utiliza também como recurso a história de vida, fundamentada em raízes antropológicas e psicanalíticas, realizando o diálogo com os mais diversos saberes e especialidades na construção das análises.

$\mathrm{O}$ despertar pelo interesse da leitura de cada capítulo inicia-se pelos títulos convidativos e provocativos. Os capítulos foram construídos de tal forma que cada uma se refere a um período específico (décadas) do recorte temporal selecionado pela autora. A 